\title{
Influence of Mixing Recycled Polycarbonate to Charpy Impact Properties at Increased Temperature
}

\author{
Vojtech Senkerik ${ }^{1, *}$, Adam Skrobakt $^{2}$, and Tomas Fiala ${ }^{1}$ \\ ${ }^{1}$ Tomas Bata Univerzity in Zlin, TGM 5555, 76001 Zlin, Czech Republic
}

\begin{abstract}
This article deals with influence of amount of mixing recycled material with virgin polycarbonate to impact properties. The aim is to perform an experiment in which the products of the studied polymer will be grinded to recycled material and then reprocessed into new specimens. These are then subjected to Charpy impact properties at increased temperatures. Several mixtures differing in the content of recycled material in virgin polycarbonate were prepared. One mixture was from pure recycled polycarbonate. The most used technology made testing samples for production of plastic products, which is injection moulding. Testing was conducted at increased temperatures $60{ }^{\circ} \mathrm{C}$. This temperature was choose because many products are used at this temperatures. The impact of added recycled material to virgin polypropylene not significant for all impact properties.
\end{abstract}

\section{Introduction}

The significant development of the production and application of polymer materials began after massive usage of polymers. Over the next few decades, plastics and their processing have significantly developed. Nowadays, polymeric materials are a part of everyday life, and in some cases their use is irreplaceable.

A variety of technologies processes polymers. The core products include injection technology. This technology provides the ability to produce precise and complex (thin-walled) products without the need for further machining. The entire injection cycle is relatively fast and can be fully automated.

The positives of polymer materials are exported in many negative ways. One of the world's major problems is the question of polymer waste and its processing. Globally, there is a production of large amounts of such waste.

Therefore, there is an increasing tendency to find possibilities for further processing and application of these secondary polymeric raw materials. The number of companies endeavouring to at least partially process these materials is still growing. In most cases, an emphasis is placed on identifying potential recycling before the production of new products. [1-4]

The material used here falls into the group of midrange engineering plastics. Polycarbonate is used in a very wide range of applications. A great advantage is good mechanical properties at an acceptable cost of manufacturing this material. Despite the increasing processing of secondary materials, there are also growing demands on such made products. Not only the required performance, but also the processing, appearance, methods of further recycling, and more.

The work deals with the possibility of using a secondary raw material in the production of full-fledged injection products. The requirements for the material of the resulting injected product are prescribed. In general, secondary raw materials do not have to meet the specified values separately. Properties can be customized by combining them with the original virgin material. The aim is to find a suitable mixture made using an available recycled material. The observed properties are notch impact properties. On the basis of the physicalmechanical properties test, the resulting mixture could be chosen which could meet the requirements of this polymer material when is used at the elevated temperature of this product. [5-8]

\section{Experiment}

This article deals with influence of amount of mixing recycled material with virgin polycarbonate to Charpy impact properties. The goal is to perform an experiment in which the products of the studied polymer will be grinded to recycled material and then reprocessed into new specimens. These are then subjected to Charpy impact properties at increased temperatures $60{ }^{\circ} \mathrm{C}$. This temperature was choose because many products are used at this temperatures.

\subsection{Testing}

The mechanical testing was Charpy impact notch test. Testing was performed on the Resil Impact Junior testing machine from company CEAST (Fig. 1). The tests were 
carried out according to ISO 179. Preparation of individual samples proceeded before each testing. It consisted of making of notch in specimens. Notch was shaped into V-shape with depth of $2 \mathrm{~mm}$.

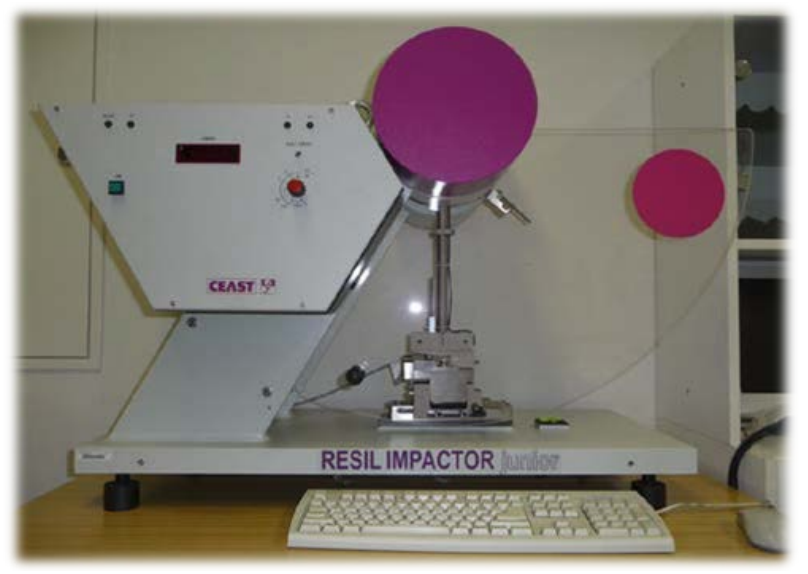

Fig. 1. CEAST Resil Impactor Junior.

Impact tests measure the ability of a material to withstand a high velocity impact, for example, as might be experienced by a plastic kettle dropped from a kitchen worktop. Again, standard methods and specimens are employed; the results give a measure of the toughness of materials. Generally, the methods used fall into two categories. In one, a pendulum strikes a sample and the energy required to break the test piece in one pendulum swing is noted. This is most often seen on data sheets as Charpy or Izod impact tests. Both Charpy and Izod use a standard striking energy.

Samples be notched, the size and shape of the notch is also standardised. This ensures that the samples fracture. The method involves dropping free falling weights onto samples. Free falling drop tests allow higher velocities and impact energies to be achieved. Useful data can also be gathered by doing impact tests at different temperatures as often this reflects more accurately the kind of environmental conditions the plastic will be subject to. For example, how a car bumper performs under impact at $25{ }^{\circ} \mathrm{C}$ may be different to how it performs at $-10^{\circ} \mathrm{C}$. It may become more brittle at low temperatures. Whatever impact test method is employed, polymer degradation should, like tensile testing, show up as a reduction in the property measured. [4]

\subsection{Tested material}

Tested material is polycarbonate. This polymer belongs to a group of thermoplastics. It is a linear polycarbonate based on bisphenol A.

Polycarbonate is a very durable material. The outstanding characteristic of PH-HT is its high heat resistance which is combined with great transparency, slight inherent colour, good flow properties and high impact strength, but it has low scratch-resistance and so a hard coating is applied to polycarbonate eyewear lenses and polycarbonate exterior automotive components.

This material is recycled and added to same virgin polycarbonate in different levels of content. [6]

Table 1. Tested mixtures.

\begin{tabular}{|c|c|}
\hline $\begin{array}{c}\text { Recycled material } \\
\text { content [\%] }\end{array}$ & Mixture \\
\hline $\mathbf{0}$ & $100 \%$ virgin polycarbonate \\
\hline $\mathbf{2 0}$ & $\begin{array}{c}80 \% \text { virgin polycarbonate } \\
+20 \% \text { recycled material }\end{array}$ \\
\hline $\mathbf{3 0}$ & $\begin{array}{c}70 \% \text { virgin polycarbonate } \\
+30 \% \text { recycled material }\end{array}$ \\
\hline $\mathbf{5 0}$ & $\begin{array}{c}50 \% \text { virgin polycarbonate } \\
+50 \% \text { recycled material }\end{array}$ \\
\hline $\mathbf{1 0 0}$ & $100 \%$ recycled material \\
\hline
\end{tabular}

\subsection{The specimens}

The specimens were prepared by the injection molding technology on the injection molding machine Arburg Allrounder 420C. Each of the specimens were left to condition for $24 \mathrm{~h}$ before testing by the following methods.

Table 2. Process parameters.

\begin{tabular}{|c|c|}
\hline Melt temperature & $300^{\circ} \mathrm{C}$ \\
\hline Mold temperature & $100^{\circ} \mathrm{C}$ \\
\hline Ejection temperature & $130{ }^{\circ} \mathrm{C}$ \\
\hline $\begin{array}{l}\text { Injection speed / } \\
\text { pressure }\end{array}$ & $\begin{array}{l}60 \mathrm{~mm} \cdot \mathrm{s}^{-1} / \\
80 \mathrm{MPa}\end{array}$ \\
\hline $\begin{array}{l}\text { Holding pressure time } \\
\text { / pressure }\end{array}$ & $30 \mathrm{~s} / 35 \mathrm{MPa}$ \\
\hline Cycle time & $55 \mathrm{~s}$ \\
\hline
\end{tabular}

\section{RESULTS}

All graphs shows the values in percentages, while virgin polycarbonate represents $100 \%$. Other values are derived from the nominal values.

\subsection{Charpy impact notch strength}

The first evaluated parameter is the Charpy impact notch strength used in deflection at the maximum impact force marked as $A m$. The virgin polycarbonate has an impact strength of $6 \mathrm{~kJ} / \mathrm{m}^{2}$ at $60^{\circ} \mathrm{C}$.

This value is highest compared to other recycled mixtures. Increasing of the recycled content in the virgin 
polycarbonate reduces this impact strength. The $20 \%$ mixture shows a drop of nearly $4 \%$ lower than reference material.

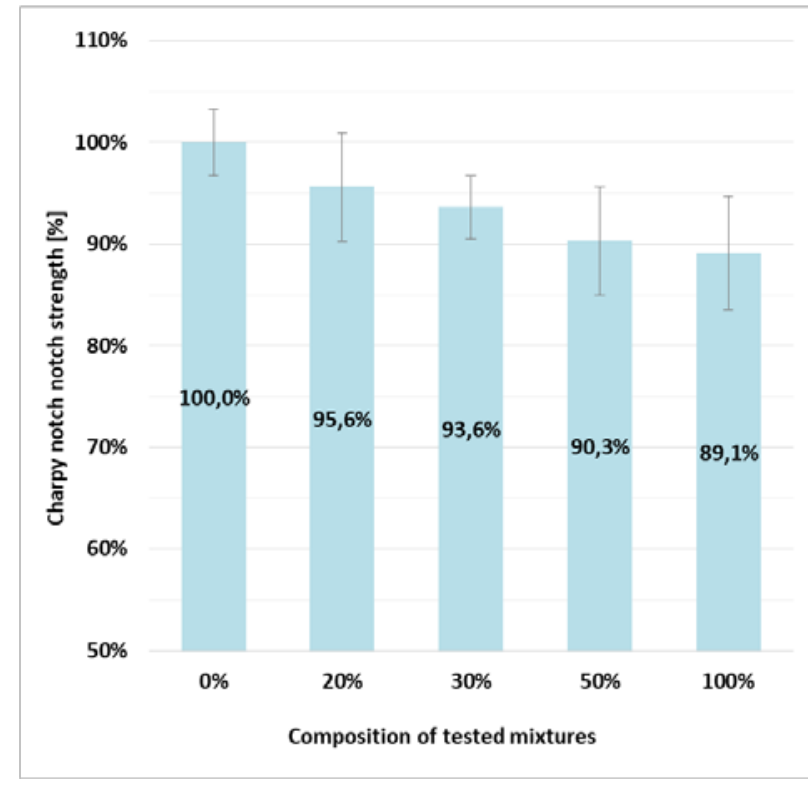

Fig. 2. Charpy impact notch strength.

Mixing an additional $10 \%$ recycled material will cause the impact strength to deteriorate by another $2 \%$. $50 \%$ recycled material adding to the virgin polycarbonate cause the value drop by almost $10 \%$. On the other hand, the $100 \%$ recycled mixture exhibits a reduction in impact strength of only one percentage point relative to the mixture containing $50 \%$ recycled material.

Table 3. Charpy impact notch strength.

\begin{tabular}{|c|c|c|}
\hline Mixture & $\begin{array}{c}\text { Arithmetic } \\
\text { mean }\left[\mathbf{k J} / \mathbf{m}^{2}\right]\end{array}$ & $\begin{array}{c}\text { Standard } \\
\text { deviation } \\
{\left[\mathbf{k J} / \mathbf{m}^{2}\right]}\end{array}$ \\
\hline $0 \%$ & 6,00 & 0,39 \\
\hline $20 \%$ & 5,74 & 0,61 \\
\hline $30 \%$ & 5,62 & 0,35 \\
\hline $50 \%$ & 5,42 & 0,58 \\
\hline $100 \%$ & 5,35 & 0,6 \\
\hline
\end{tabular}

There is no such high deterioration in the measured values. $100 \%$ recycled polycarbonate shows a drop of values over $10 \%$.

Further note that can be seen from the Fig. 2 is that mixtures with recycled additive exhibit greater variations in measured values than the virgin polycarbonate.

\subsection{Maximum impact force}

Another evaluated property is the maximum impact force exerted by the striking edge on the test specimen in the impact direction marked as $F m$. The highest measured force is $224.5 \mathrm{~N}$. This value does not show the virgin polycarbonate - but the mixture with the admixture $20 \%$ recycled material. This mixture has only one percent better impact force than the virgin polycarbonate. The mixture with $30 \%$ addition of recycled material shows a reduction in the measured values over two percent.

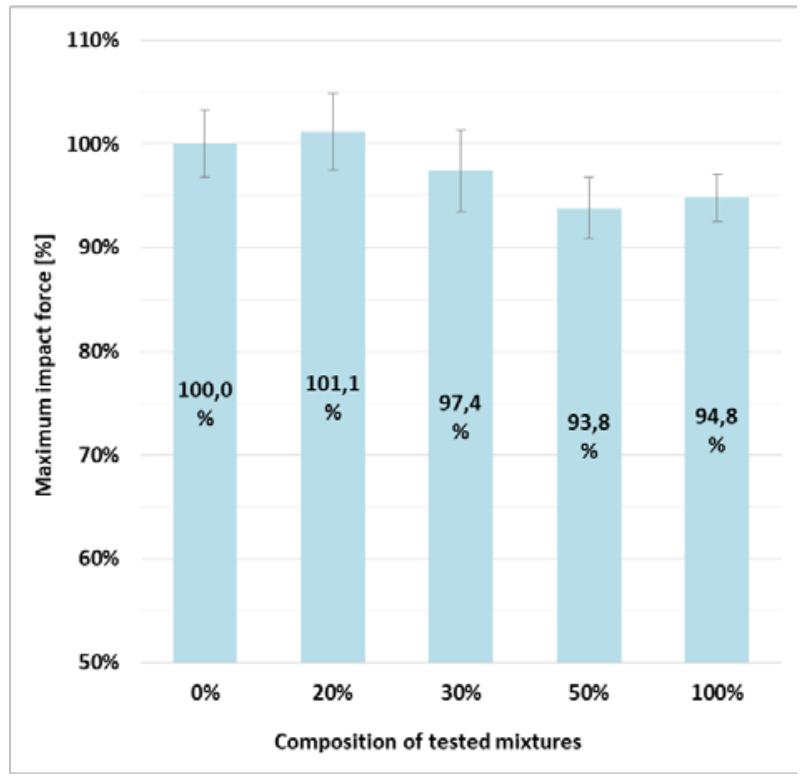

Fig. 3. Maximum impact force.

The lowest measured maximum force is for the mixture with $50 \%$ added recycled material, which is less than $6 \%$ than the virgin polycarbonate. Even the mixture from $100 \%$ recycled polycarbonate show better measured maximum force value. This mixture has a higher value of one percent.

All mixtures with admixture of recycled material do not show such a visible decrease in values as for impact notch strength $\mathrm{Am}$.

Table 4. Maximum impact force.

\begin{tabular}{|c|c|c|}
\hline Mixture & $\begin{array}{c}\text { Arithmetic } \\
\text { mean [N] }\end{array}$ & $\begin{array}{c}\text { Standard } \\
\text { deviation [N] }\end{array}$ \\
\hline $0 \%$ & 224,5 & 14,5 \\
\hline $20 \%$ & 227,0 & 16,8 \\
\hline $30 \%$ & 218,6 & 17,1 \\
\hline $50 \%$ & 210,6 & 12,3 \\
\hline $100 \%$ & 212,9 & 9,7 \\
\hline
\end{tabular}

For this measurement, measured values of the maximum force show approximate the same standard deviations for all mixtures with the recycled material including the virgin polycarbonate.

\subsection{Deflection at maximum impact force}


Deflection at maximum impact force is another evaluated property marked as $s_{m}$. The lowest deflection value is the virgin polycarbonate and it is $1.95 \mathrm{~mm}$. Other mixtures with the addition of the recycled material exhibit relatively large deflection changes, the largest deflection reaching the mixture with $50 \%$ recycled material. The deflection increased in the Charpy testing more than $8 \%$ for this mixture.

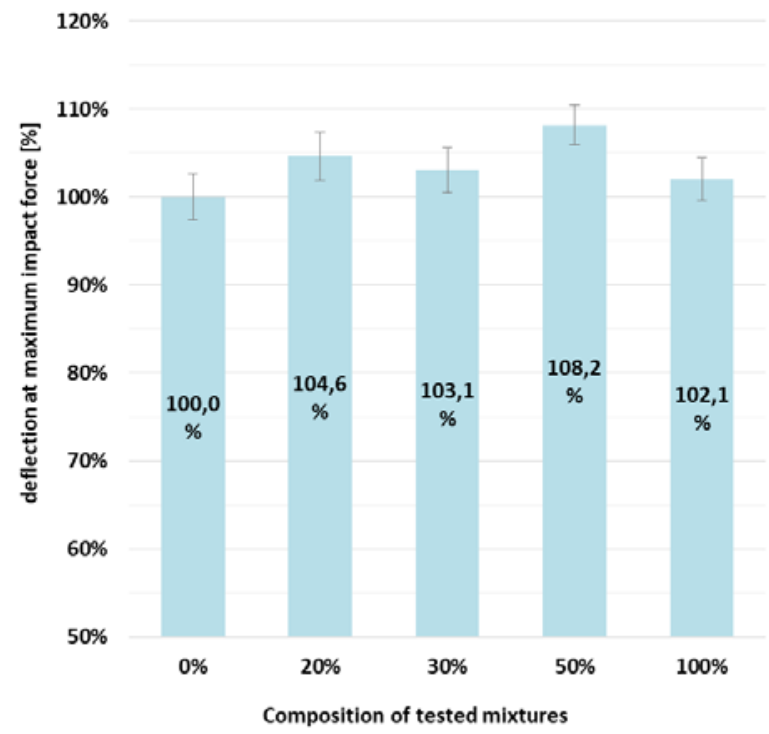

Fig. 4. Deflection at maximum impact force.

The second most deformed samples at $F m$ show mixture with $20 \%$ recycled material, almost $5 \%$ more deformed than the virgin polycarbonate. The mixture with $30 \%$ recycled material has a deflection of $3 \%$ at maximum force.

Table 5. Deflection at maximum impact force.

\begin{tabular}{|c|c|c|}
\hline Mixture & $\begin{array}{c}\text { Arithmetic } \\
\text { mean [mm] }\end{array}$ & $\begin{array}{c}\text { Standard } \\
\text { deviation } \\
\text { [mm] }\end{array}$ \\
\hline $0 \%$ & 1,95 & 0,1 \\
\hline $20 \%$ & 2,04 & 0,11 \\
\hline $30 \%$ & 2,01 & 0,1 \\
\hline $50 \%$ & 2,11 & 0,09 \\
\hline $100 \%$ & 1,99 & 0,09 \\
\hline
\end{tabular}

On the other hand, the smallest deflection from recycled mixtures shows the $100 \%$ recycled mixture.

Measured data for all mixtures shows almost the same scatter of measured data.

When comparing the data from the impact strength $A m$ with the $s_{m}$ deflection, it can be observed that the measured mixtures have less impact strength and even more are deformed.

\section{Conclusions}

This paper describes influence of amount of mixing recycled material with virgin polycarbonate to impact properties. The experiment shows changes of Charpy impact properties with changing of amount of recycled material. Testing was carried out at increased temperatures $60^{\circ} \mathrm{C}$.

Recycled material was obtained by grinding of technological waste. One mixture was from pure recycled material. Tested material was PC-HT.

The influence of added recycled material to virgin polypropylene is mostly visible for Charpy impact notch strength. Mixture with $100 \%$ recycled material has got nearly $11 \%$ decrease of value this property. The other mixtures show a progressive decrease in impact strength with decreasing content of the virgin polycarbonate.

Other two properties maximum impact force and deflection at maximum impact force are not so influenced like the first described property and there are not visible differences between prepared recycled mixtures.

This work was supported by the European Regional Development Fund under the project CEBIA-Tech Instrumentation No. CZ.1.05/2.1.00/19.0376 and by the Ministry of Education, Youth and Sports of the Czech Republic within the National Sustainability Program project no. LO1303 (MSMT-7778/2014). Moreover, it was supported by the Internal Grant Agency of TBU in Zlin: no. IGA/FT/2018/012.

\section{References}

1. V. Goodship, Introduction to plastics recycling. 2nd ed. Shawbury, U.K.: Smithers Rapra, (2007), 174 p. ISBN 978-1-84735-078-7.

2. F. P. La Mantia. Recycling of plastic materials. Toronto: ChemTec Pub., (1993), VI, 189 p. ISBN 18-951-9803-8

3. Scelsi, L; Hodzic, A; Soutis, C; Hayes, S.A; Rajendran, S; Alma'adeed, M.A; Kahraman, R. A Review on Composite Materials Based on Recycled Thermoplastics and Glass Fibres. Plastics, Rubber and Composites. (2011), vol. 40, ISSN:1465-8011.

4. M. Manas, D. Manas, M. Stanek, S. Sanda, V. Pata, (2011), Chemicke listy, Volume 105, Issue 17, pp. S828-S829

5. M. Ovsik, M. Stanek, V. Janostik, M. Reznicek. (2018) MM Science Journal, 2018 (March), pp. 2149-2152.

6. V. Senkerik et al., Advanced Materials Research, Vols. 1025-1026, pp. 274-277, (2014)

7. M. Ovsik, M. Stanek, M. Reznicek, L. Hylova. (2018) Materials Science Forum, 919, pp. 103-110.

8. M. REZNICEK, M. BEDNARIK, L. HYLOVA and D. MANAS., MATEC Web of Conferences (2016). 